\title{
Biologically relevant sex differences for fitness-related parameters in active octogenarians
}

\author{
Fabian Lötscher · Tobias Löffel · Roger Steiner • \\ Michael Vogt · Stephan Klossner • Albrecht Popp • \\ Kurt Lippuner · Hans Hoppeler · Christoph Däpp
}

\begin{abstract}
Accepted: 27 November 2006/ Published online: 12 January 2007
\end{abstract}
(C) Springer-Verlag 2006

\begin{abstract}
The number of elderly people is growing in western populations, but only few maximal performance data exist for people $>75$ years, in particular for European octogenarians. This study was performed to characterize maximal performance of 55 independently living subjects (32 women, $81.1 \pm 3.4$ years; 23 men, $81.7 \pm 2.9$ years) with a focus on sex differences. Maximal performance was determined in a ramp test to exhaustion on a bicycle ergometer with ergospirometry, electrocardiogram and blood lactate measurements. Maximal isometric extension strength of the legs (MEL) was measured on a force platform in a seated position. Body composition was quantified by X-ray absorptiometry. In $>25 \%$ of the subjects, serious cardiac abnormalities were detected during the ramp test with men more frequently being affected than women. Maximal oxygen consumption and power output were $18.2 \pm 3.2$ versus $25.9 \pm 5.9 \mathrm{ml} \mathrm{min}^{-1} \mathrm{~kg}^{-1}$ and $66 \pm 12$ versus $138 \pm 40 \mathrm{~W}$ for women versus men, with a significant sex difference for both parameters. Men outperformed women for MEL with $19.0 \pm 3.8$ versus $13.6 \pm 3.3 \mathrm{~N} \mathrm{~kg}^{-1}$. Concomitantly, we found a higher proportion of whole body fat in women $(32.1 \pm 6.2 \%)$ compared to men $(20.5 \pm 4.4 \%)$. Our study extends previously available maximal performance data for endurance and strength to indepen-
\end{abstract}

F. Lötscher · T. Löffel · R. Steiner · M. Vogt

S. Klossner · H. Hoppeler · C. Däpp ( $\square)$

Institute of Anatomy, University of Bern,

Baltzerstrasse 2, 3000 Bern 9, Switzerland

e-mail: daepp@ana.unibe.ch

A. Popp · K. Lippuner

Osteoporosis Policlinic, University Hospital of Bern,

3010 Bern, Switzerland dently living European octogenarians. As all sexrelated differences were still apparent after normalization to lean body mass, it is concluded that it is essential to differentiate between female and male subjects when considering maximal performance parameters in the oldest segment of our population.

Keywords Elderly $\cdot$ Exercise $\cdot$ Maximal performance $\cdot$ Maximal oxygen consumption

\section{Introduction}

The portion of elderly in all western communities is increasing and thus the characterization of their physical work capacity becomes increasingly important. Physical work capacity is known to decline with age (Farazdaghi and Wohlfart 2001). According to the American Heart Association, i.e., maximum values of maximal oxygen consumption $\left(V_{\mathrm{O}_{2} \max }\right)$ occur between the ages of 15 and 30 years and decrease with an average decline of $6-12 \%$ per decade, in both sedentary and athletic populations (Fletcher et al. 2001; Rogers et al. 1990; Wiswell et al. 2001). Incremental exercise tests are commonly used to quantify the function of the cardio-respiratory system and to diagnose its diseases. In elderly, these tests are likely to be performed as ramp tests with continuous increase of the load on bicycle ergometers because testing to exhaustion on treadmills may become more and more difficult for frail elderly (Cicoira et al. 2001). Several studies present reference values for exercise tests for all age classes (Farazdaghi and Wohlfart 2001; Buskirk and Hodgson 1987; Nordenfelt et al. 1985; Wohlfart and Farazdaghi 2003). But values for subjects in the old age ( $>75$ years) are generally extrapolated 
from data points of younger subjects, taking body weight, height, age and maximal workload into account. To our knowledge, only very few actually measured data exist for this age category (Evans et al. 2005; Malbut et al. 2002; Ehsani et al. 2003) whereby only few studies have emphasized the importance of total body composition, e.g., with inclusion of dual X-ray absorptiometry (DXA) measurements (Neder et al. 1999). In many studies, people with regular intake of medication or with a medical history of cardiac, respiratory or neuromuscular diseases were excluded (Farazdaghi and Wohlfart 2001; Nordenfelt et al. 1985, 1999; Wohlfart and Farazdaghi 2003; Simar et al. 2005). This approach can lead to a sample population not representing an average population of people of this age in which regular intake of medication is frequently observed. Recently published studies with European people in most advanced age have been conducted with a very small population ( $N=10-17)$ (Farazdaghi and Wohlfart 2001; Wohlfart and Farazdaghi 2003; Simar et al. 2005) but sex differences were neglected (Simar et al. 2005). The aim of this study was to characterize the maximal physical work capacity (endurance and strength) and body composition in a segment of independently living female and male elderly people ( $>75$ years) with a focus on sex differences.

\section{Methods}

\section{Subjects and study design}

The data presented were recorded from active subjects in stable health condition, willing to enter the Swiss National Foundation Program 53 "Musculoskeletal health and chronic pain". The subjects were recruited from the University of the Third Age (all $>60$ years) in Bern, Switzerland, and from local exercise groups for elderly. The study was approved by the local ethical committee and subjects provided written consent to participate in this study.

Initially, 55 independently living voluntary subjects (32 women, 23 men) between 75 and 89 years with stable medication, able to reach the test facilities unaided were included in the study. Subjects with severe diseases, i.e., neuromuscular diseases, myocardial infarction and/or severe hip or knee arthrosis, showing a significant negative impact on physical exercise were excluded from participation. All the subjects were asked to continue usual medication over the test period. In a clinical examination, a physician recorded the anthropometric data, took a medical history and a complete physical status. Whole body composition (lean and fat tissue mass) was determined using DXA (QDR-4500A, Hologic Inc., Bedford, USA).

\section{Exercise testing}

\section{Timed Up \& Go test and Berg balance scale}

The Timed Up \& Go (TUG) (Shumway-Cook et al. 2000) and the Berg balance scale (BBS) (Steffen et al. 2002; Berg et al. 1992) are age-specific tests for community-dwelling elderly people to assess general mobility and the risk for falling. For both tests, verbal instruction was given to the subjects prior to the different tasks whereas during the task no additional encouragement was administered. For the TUG, the time was measured, which was needed for getting up from an armchair, walking safely a distance of $3 \mathrm{~m}$, returning to the chair and sitting down again (Shumway-Cook et al. 2000). After one test trial, the better of two trials was taken for the analysis. For the BBS, 14 items (interview combined with execution of balance, coordination and strength tasks) were scored on a scale of 0-4 (Berg et al. 1992).

\section{Ramp test to exhaustion}

A continuous ramp test to exhaustion was performed on an electromagnetically braked bicycle ergometer (Ergoline 800S, Ergoline GmbH, Bitz, Germany). The test started with a period of rest followed by a $2 \mathrm{~min}$ warm-up without load. The initial exercise load of $20 \mathrm{~W}$ was increased in a linear ramp pattern with $5 \mathrm{~W}$ every 20-60 s, dependent on the subject's individual fitness level, such that the total test duration would be 6-12 min (Fletcher et al. 2001). The subjects were asked to continuously pedal until exhaustion, maintaining constant revolutions-per-minute $>45$. Gas exchange parameters and ventilatory variables were recorded breath-by-breath (Oxicon alpha, Jäger GmbH, Würzburg, Germany). A 12-lead electrocardiogram (CardioSoft, GE, Houston, Texas, USA) was recorded in lying position before and during the ramp test sitting on the ergometer. Systolic and diastolic blood pressure and blood lactate levels (Lactate Pro, Axon Lab AG, Baden, Switzerland) were taken at rest and at the end of the test. Systolic and diastolic blood pressure and rating of perceived exertion (BORG, scale 6-20) were additionally recorded every $2 \mathrm{~min}$ (Borg 1982). By applying rigorous standards for BORG, lactate and RER at the end of the ramp test (see Table 1) we ascertained that the incremental exercise tests were performed to exhaustion. 


\section{Maximal isometric strength}

Maximal isometric extension strength of the legs (MEL) was measured by pushing against a force platform (Quattro Jump ${ }^{\circledR}$, Kistler Instrumente AG, Winterthur, Switzerland) in a sitting position on a chair (Fig. 1). This setup with a closed chain measurement of muscle extension strength of the legs was chosen to minimize the stress produced in the knee joint by a single joint measurement, i.e., an isometric assessment of quadriceps strength as well as to avoid strain imposed on the vertical column such as with a subject strapped into a leg press. The subjects were positioned on the chair so that the lower limb joint angles (foot, knee and hip) were at $90^{\circ}$ and they were fixed in this position with a seatbelt. They were asked to push maximally against the force platform (hip and knee extension) and to maintain the contraction for about 3$4 \mathrm{~s}$. Force data from 3 to 4 trials were recorded with a resolution of $500 \mathrm{~Hz}$. The highest average force over a 1-s period was assigned as the subject's MEL.

\section{Data analysis}

Data are presented as mean \pm standard deviation. Sexgrouped data were compared using Student's $t$ test. The level for significance was set at $P<0.05$.

For comparison of our measured data with predicted values for this age group, anthropometric data of our subjects were used in the following formulas proposed by the respective authors: for falling (TUG and BBS), and maximal work capacity (performance and strength) are reported in Table 1.

\section{Anthropometric data}

The subjects' overall mean values for age, weight and height were $81.3 \pm 3.8$ years, $\quad 69.2 \pm 11.5 \mathrm{~kg}$ and $166 \pm 10 \mathrm{~cm}$, respectively. Men were significantly heavier $(+8.0 \mathrm{~kg})$ and taller $(+15.0 \mathrm{~cm})$ than women. No significant difference was observed for the body mass index (BMI) whereas DXA results showed that females had a significantly higher proportion of fat tissue than male subjects, with a remarkable difference of $+59 \%$.

The different categories of drugs taken by the subjects are listed in Table 2. No significant difference between the sexes was observed for the number of medication products taken by the subjects. Most frequently consumed drugs were acetyl-salicylic acids $(n=22)$ and diuretics $(n=13)$ whereas beta-blockers were taken by 8 of the 55 subjects. Less than $10 \%$ ( 5 out of 55) did not take any drugs on a regular basis.

Assessment of general shape and risk for falling

Mean duration in the TUG was $8.2 \pm 1.6 \mathrm{~s}$ and mean score in the BBS was $53.5 \pm 3.1$ pts with no significant difference between females and males.

\section{Ramp test}

Only 3 out of 55 subjects ( 2 females, 1 male) completed the ramp test with $\mathrm{BORG}<15$ and lactate le-

Neder et al. (1999):

$$
\begin{array}{ll}
\text { Neder et al. (1999): } & V_{\mathrm{O}_{2} \max } \text { men }=-24.3 \times \text { age }+12.5 \times \text { body mass }+9.8 \times \text { height }+702 \\
& V_{\mathrm{O}_{2} \max } \text { women }=-13.7 \times \text { age }+7.5 \times \text { body mass }+7.4 \times \text { height }+372 \\
& P_{\max } \operatorname{men}=-1.78 \times \text { age }+0.65 \times \text { body mass }+1.36 \times \text { height }-45.4 \\
& P_{\max } \text { women }=-1.19 \times \text { age }+0.96 \times \text { height }+28.1 \\
\text { Wohlfart and Farazdaghi (2003): } & P_{\max } \operatorname{men}=[244.6 \times(\text { height } / 100)-92.1] /\left[1+e^{0.038(\text { age }-77.3)}\right] \\
& P_{\max } \text { women }=[137.7 \times(\text { height } / 100)-23.1] /\left[1+e^{0.064(\text { age }-75.9)}\right] \\
& V_{\mathrm{O}_{2} \max } \operatorname{men}=(-0.31 \times \text { age })+44.23 \\
\text { Paterson et al. (1999): } & V_{\mathrm{O}_{2} \max } \text { women }=(-0.25 \times \text { age })+36.63 \\
& V_{\mathrm{O}_{2} \max } \text { men }=[18.4-(0.16 \times \text { age })] \times 3.5
\end{array}
$$$$
\text { Paterson et al. (1999): } \quad V_{\mathrm{O}_{2} \max } \operatorname{men}=(-0.31 \times \text { age })+44.23
$$$$
\text { Myers et al. (2002): }
$$

with $V_{\mathrm{O}_{2} \max }\left(\mathrm{ml} \mathrm{min}{ }^{-1}\right), P_{\max }(\mathrm{W})$, body mass $(\mathrm{kg})$, height $(\mathrm{cm})$ and age (years).

\section{Results}

The data of all female and male subjects for anthropometry, assessment of fitness, mobility level and risk vel $<3.0 \mathrm{mM}$ or a respiratory exchange ratio (RER) $\leq 1.0$. As a consequence, their tests were classified as submaximal and therefore excluded from the analyses. For the remaining subjects $(n=52)$, mean exercise duration was 8:51 $\pm 1: 34 \mathrm{~min}$ and in the end of the ramp test mean BORG, lactate level and RER were $16.0 \pm 2.0, \quad 4.9 \pm 1.7$ and $1.17 \pm 0.08 \mathrm{mM}$, respectively. Mean values for $V_{\mathrm{O}_{2} \max }, P_{\max }$, maximal 
Table 1 Anthropometric and functional data for females and males

\begin{tabular}{|c|c|c|c|c|c|}
\hline & \multicolumn{2}{|l|}{ Women } & \multicolumn{2}{|l|}{ Men } & \multirow[t]{2}{*}{$P$ value } \\
\hline & Mean \pm SD & Range & Mean \pm SD & Range & \\
\hline Anthropometric data & $n=32$ & & $n=23$ & & \\
\hline Age (years) & $81.1 \pm 3.4$ & $75-89$ & $81.7 \pm 2.9$ & $76-87$ & 0.50 \\
\hline Body mass (kg) & $65.8 \pm 11.5$ & $49-97$ & $73.8 \pm 9.7 *$ & $60-98$ & $<0.01$ \\
\hline Height $(\mathrm{cm})$ & $160.0 \pm 6.1$ & $146-175$ & $175.0 \pm 6.9 *$ & $161-187$ & $<0.01$ \\
\hline BMI $\left(\mathrm{kg} \mathrm{m}^{-2}\right)$ & $25.8 \pm 4.8$ & $18.4-38.9$ & $24.1 \pm 2.6$ & $19.2-28.0$ & 0.12 \\
\hline DXA measurement & $n=30$ & & $n=20$ & & \\
\hline Lean body mass (kg) & $41.4 \pm 4.1$ & $34.1-51.5$ & $54.7 \pm 6.1^{*}$ & $44.8-68.6$ & $<0.01$ \\
\hline Fat mass $(\%)$ & $32.4 \pm 6.2$ & $15.1-44.8$ & $20.4 \pm 4.4^{*}$ & $13.4-28.9$ & $<0.01$ \\
\hline Timed Up \& Go (TUG) & $n=32$ & & $n=23$ & & \\
\hline TUG (s) & $8.3 \pm 1.6$ & $5.7-12.1$ & $8.0 \pm 1.7$ & $6.3-12.2$ & 0.50 \\
\hline Berg balance scale (BBS) & $n=29$ & & $n=16$ & & \\
\hline BBS (pts; 0-56) & $53.6 \pm 1.7$ & $49-56$ & $53.4 \pm 4.7$ & $36-56$ & 0.80 \\
\hline Ramp test to exhaustion & $n=30$ & & $n=22$ & & \\
\hline$P_{\max }(\mathrm{W})$ & $66 \pm 12$ & $50-95$ & $138 \pm 40^{*}$ & $70-210$ & $<0.01$ \\
\hline$V_{\mathrm{O}_{2} \max }\left(\mathrm{ml} \mathrm{min} \mathrm{min}^{-1} \mathrm{~kg}^{-1}\right)$ & $18.2 \pm 3.2$ & $10.7-25.4$ & $25.9 \pm 5.9^{*}$ & $15.2-34.8$ & $<0.01$ \\
\hline Max. heart rate $\left(\min ^{-1}\right)$ & $135 \pm 22$ & $85-166$ & $144 \pm 14$ & $111-166$ & 0.08 \\
\hline Max. oxygen pulse $\left(\mathrm{ml}\right.$ beat $\left.^{-1}\right)$ & $9.0 \pm 1.2$ & $6.6-12.2$ & $13.2 \pm 2.8^{*}$ & $8.3-18.4$ & $<0.01$ \\
\hline Max.ventilation $\left(1 \mathrm{~min}^{-1}\right)$ & $47.5 \pm 8.5$ & $32.2-63.4$ & $78.9 \pm 19.1^{*}$ & $43.9-128.2$ & $<0.01$ \\
\hline Max. respiratory exchange ratio & $1.15 \pm 0.09$ & $1.01-1.36$ & $1.19 \pm 0.07$ & $1.05-1.32$ & 0.05 \\
\hline Max. systolic blood pressure $(\mathrm{mmHg})$ & $173 \pm 21$ & $125-210$ & $178 \pm 17$ & $140-210$ & 0.36 \\
\hline Max. lactate level $\left(\mathrm{mmol} \mathrm{l}^{-1}\right)$ & $4.7 \pm 1.6$ & $2.0-8.2$ & $5.2 \pm 1.9$ & $2.9-9.7$ & 0.34 \\
\hline Max. BORG (6-20) & $15.9 \pm 2.2$ & $12.5-19$ & $16.1 \pm 1.7$ & $13-19$ & 0.68 \\
\hline Maximal isometric strength (MEL) & $n=31$ & & $n=21$ & & \\
\hline $\operatorname{MEL}\left(\mathrm{N} \mathrm{kg}^{-1}\right)$ & $13.6 \pm 3.3$ & $8.72-22.1$ & $19.0 \pm 3.8^{*}$ & $11.3-26.2$ & $<0.01$ \\
\hline
\end{tabular}

Student's $t$ test was applied for detection of significant sex differences between females and males $(*)$ with a level of significance of $P<0.05$

heart rate and maximal systolic blood pressure were $21.5 \pm 5.9 \mathrm{ml} \mathrm{min}^{-1} \mathrm{~kg}^{-1}, 96 \pm 45 \mathrm{~W}, 139 \pm 19 \mathrm{~min}^{-1}$ and $175 \pm 19 \mathrm{mmHg}$, respectively. Men significantly outperformed women for $V_{\mathrm{O}_{2} \max }(+42 \%)$ and $P_{\max }$ $(+109 \%) \cdot V_{\mathrm{O}_{2} \max }$ normalized to whole body lean mass was still significantly higher $(P<0.01 ;+17 \%)$ in men $\left(33.7 \pm 6.9 \mathrm{ml} \mathrm{min}^{-1} \mathrm{~kg}^{-1}\right.$ lean mass $)$ than in women $\left(28.9 \pm 4.1 \mathrm{ml} \mathrm{min}^{-1} \mathrm{~kg}^{-1}\right.$ lean mass $)$. Likewise, a significant sex dependence was apparent for oxygen pulse and ventilation whereas no significant differences were observed for maximal heart rate, systolic blood pressure, end lactate level and RER (see Table 1 for overview).

\section{ECG measurements}

During the maximal exercise tests, cardiac abnormalities (signs of myocardial ischemia and/or arrhythmias) were observed in 14 subjects (five occurred in women and nine in men). Three major cardiac abnormalities with signs for serious myocardial ischemia (st segment depression and/or ventricular arrhythmias) were observed in men. After the ramp test, all subjects presenting cardiac abnormalities were sent to a cardiologist for further examination.

\section{Maximal isometric strength}

Mean MEL was $15.8 \pm 4.4 \mathrm{~N} \mathrm{~kg}^{-1}$ being significantly higher $(+40 \%)$ in men than in women (see Table 1 ). When MEL was normalized to lean body mass the sex dependent difference in force production was persistent $(P<0.05)$.

\section{Discussion}

The data presented in this study describes a population of elderly women and men tested to determine maximal strength and endurance as well as general mobility and balance. Females and males $>75$ years of age were included in the study when the medical condition allowed for safe testing and when medications were taken on a long term bases. Less than $10 \%$ of our subjects received no medication. In the analysis, we specifically focused on performance differences between female and male subjects. The study was conducted with a relatively large population of 55 active and independently living subjects (32 women and 23 men), considerably more than in other studies with subjects of similar age [Simar et al. (2005): $N=17$ ]. 


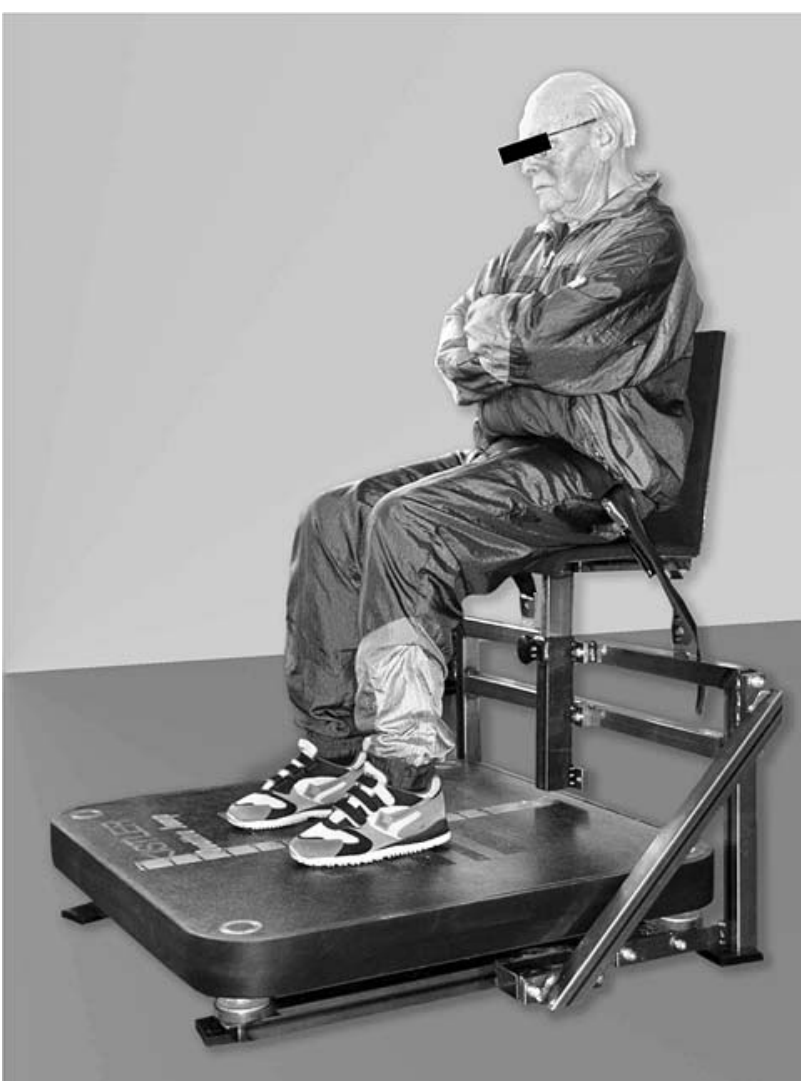

Fig. 1 Maximal isometric extension strength of the legs (MEL). Measurement of MEL (hip and knee extension) on a force platform (Quattro Jump ${ }^{\circledR}$, Kistler Instrumente AG, Switzerland) in a seated position at $90^{\circ}$ for the lower limb joint angles (foot, knee and hip)

Table 2 Frequency count of medication taken by the subjects on a regular basis

\begin{tabular}{llllll}
\hline & \multicolumn{2}{l}{ Women, $n=32$} & & \multicolumn{2}{c}{ Men, $n=23$} \\
\cline { 2 - 3 } \cline { 5 - 6 } & $n$ & $\%$ & & $n$ & $\%$ \\
\hline Beta blockers & 6 & 19 & & 2 & 9 \\
Statins & 5 & 16 & & 5 & 22 \\
Diuretics & 8 & 25 & & 5 & 22 \\
$\mathrm{Ca}^{2+}$ channel blockers & 6 & 19 & & 2 & 9 \\
ACE inhibitors & 5 & 16 & & 3 & 13 \\
Angiotensin II antagonists & 8 & 25 & & 4 & 17 \\
Coumarins & 2 & 6 & & 4 & 17 \\
ASA & 12 & 38 & & 10 & 43 \\
\hline
\end{tabular}

$A S A$ acetyl-salicylic acid

Our results show significant differences between male and female subjects for body composition (proportion of fat) and for maximal work capacity. Men significantly outperformed women in $V_{\mathrm{O}_{2} \max }, P_{\max }$ and MEL. A presentation of maximal physical performance values (Simar et al. 2005) without differentiation between male and female subjects in this age group is therefore of limited value. It is important to note that this differentiation between male and female subjects still remains relevant after normalization to lean body mass estimated by DXA measurement, for $V_{\mathrm{O}_{2} \max }$ $(+17 \%), P_{\max }(+58 \%)$ and MEL $(+19 \%)$. The sexspecific differences are noteworthy as in younger subjects sex-specific differences for $V_{\mathrm{O}_{2} \max }$ are known to disappear with normalization to lean body mass (Uth 2005; Vinet et al. 2003; Washburn and Seals 1984). Vinet et al. (2003) stated that differences for $V_{\mathrm{O}_{2} \max }$ between male and female children are due to differences in body composition. As this was not observed in the present study population our data suggest that differences for maximal performance parameters between male and female subjects become accentuated in old age. This notion is supported by Johnson et al. (2000) who suggested that differences for $V_{\mathrm{O}_{2} \max }$ between elderly male and female subjects after normalization to fat-free mass might be due to "factors related to cellular aerobic capacity" or "cultural differences such as levels of habitual exercise". It therefore appears that differentiation between sex (biological differences) and gender (sociocultural differences) (Torgrimson and Minson 2005) becomes increasingly important with old age as these differences could accumulate over a longer lifetime period. However, it is currently unclear whether the observed physiological differences are due to genetically determined factors or are behaviorally induced.

Our current data result in an extension of existing maximal performance values (Farazdaghi and Wohlfart 2001; Nordenfelt et al. 1985; Wohlfart and Farazdaghi 2003; Astrand 1960; Shvartz and Reibold 1990; Neder et al. 2001) to females and males $>75$ years (see Fig. 2). The data demonstrate a continuing agedependent decrease for maximal performance variables like $V_{\mathrm{O}_{2} \max }$ and $P_{\max }$, in particular for women. $V_{\mathrm{O}_{2} \max }$ values for male subjects were found to be somewhat higher than expected from a linear extrapolation of the known age-dependent decrease at lower age (Fig. 2). In male subjects, the high levels of $V_{\mathrm{O}_{2} \max }$ may be a reflection of the active lifestyle of the study population with several male subjects being actively mountaineering at the age of $>80$ years.

Our measured mean values for $V_{\mathrm{O}_{2} \max }$ were slightly higher in both females and males compared with values calculated with current formulas for prediction of maximal performance (Neder et al. 1999; Paterson et al. 1999; Myers et al. 2002) (Fig. 3). Above-average performance values of our study population $(130 \%$ of predicted exercise capacity in both men and women) are as well supported by the comparison to values from 
Fig. 2 Maximal performance values. Maximal performance values for females and males extending reference values for younger subjects from published work (Farazdaghi and Wohlfahrt 2001; Nordenfelt et al. 1985; Wohlfahrt and Farazdaghi 2003; Astrand 1960; Shvartz and Reibold 1990; Neder et al. 2001). $P_{\max }$, maximal power output; $V_{\mathrm{O}_{2} \max }$, maximal oxygen consumption
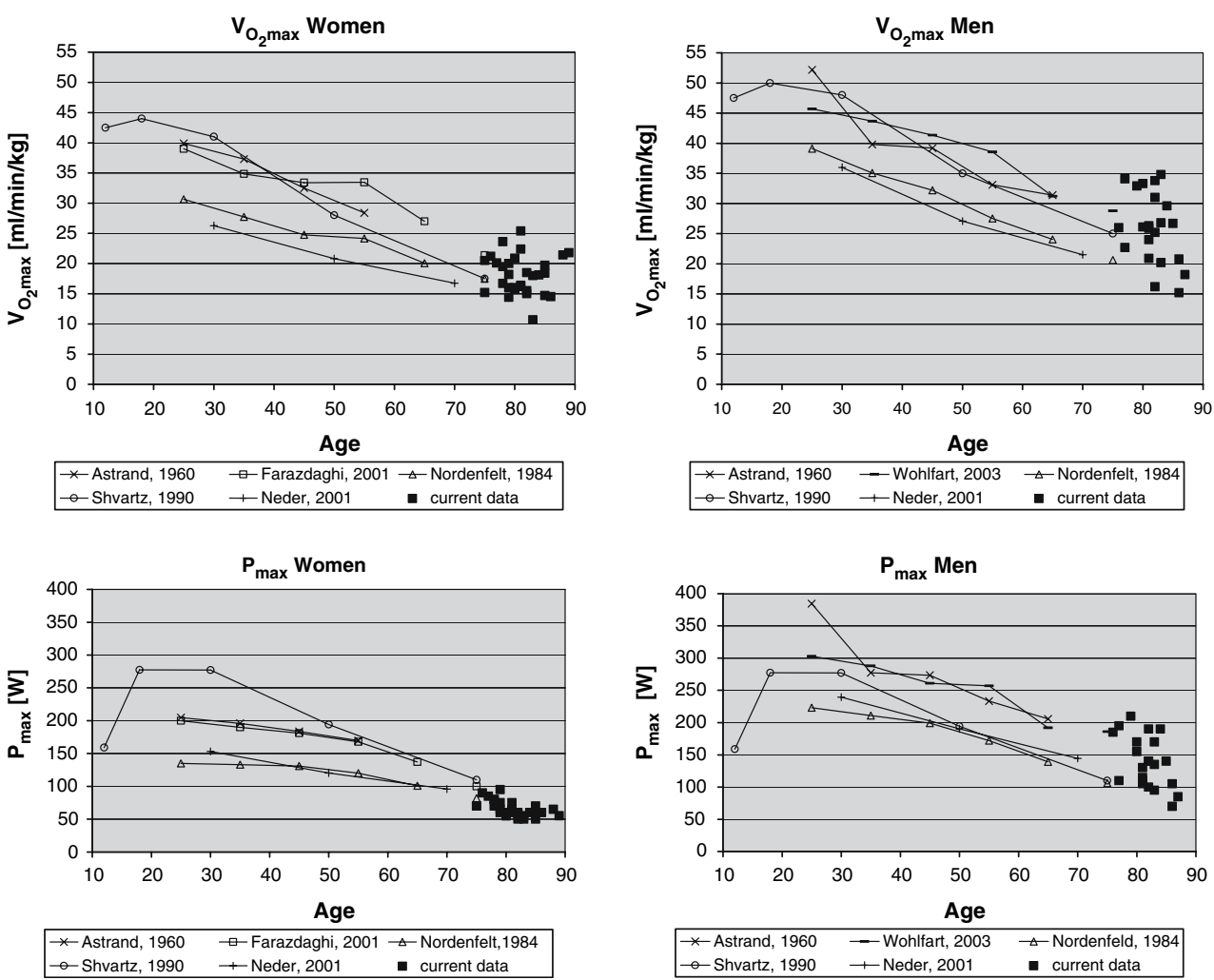

nomograms for women (Gulati et al. 2005) and men (Morris et al. 1993) assessed in large clinical studies investigating $>1,000$ patients free from apparent heart disease.

This phenomenon is not observed for $P_{\max }$ achieved in the exhaustive incremental exercise test, which was not increased compared with predicted values neither for females nor for males. This seems best explained by differences in ramp protocols applied in the cited studies (Neder et al. 1999; Paterson et al. 1999; Myers et al. 2002) while $P_{\max }$ values are likely to vary with different ramp protocols (i.e., steeper or shallower); $V_{\mathrm{O}_{2} \max }$ seems to be relatively protocol-independent as long as the total test duration remains in the range of 6-12 min (Fletcher et al. 2001).

Aging goes along with fading of physical abilities, increased occurrence of health deficits and decreased performance. Thus, testing of maximal performance parameters in elderly is potentially more risky than in younger populations. It therefore seems mandatory to adjust testing conditions (e.g., cycling instead of running and fitness level related ramp test protocols) and to take all necessary precautions for emergencies (clinical environment with ECG control and resuscitation readiness). However, under these conditions safe testing seems to be possible (for an overview, see Fletcher et al. 2001). As a consequence of the risks involved with testing old people, submaximal performance tests are often preferred (Witham and McMurdo 2003). Submaximal data can be sufficient to provide advice for exercise training of elderly. However, only testing to exhaustion yields useful $V_{\mathrm{O}_{2} \max }$ values, a strong prognostic factor for the risk of death among patients with or without cardiovascular disease (Cicoira et al. 2001; Myers et al. 2002). Furthermore, $V_{\mathrm{O}_{2} \max }$ allows a comparison of elderly-specific maximal performance data with data from younger subjects yielding quantification of the age-dependent decrease of human maximal performance parameters. As our study shows, testing to exhaustion is feasible and safe. However, the occurrence of minor to severe cardiac abnormalities for more than $25 \%$ of our elderly subjects during the ramp test to exhaustion high lightens the necessity for safety precautions and the availability of well trained medical personal during all testing procedure.

The sex difference for $V_{\mathrm{O}_{2} \max }$ and $P_{\max }$ was confirmed as well for the measures of MEL. In particular, the low mean value for MEL $\left(13.6 \mathrm{~N} \mathrm{~kg}^{-1}\right)$ in female subjects with $\sim 20 \%$ of the values being below the acceleration of gravity was impressive. It has to be considered however, that with our method for measuring MEL (devised to minimize stress on joints and vertebral column) only the vertical component of the force applied to the force platform (at an angle of approx. $45^{\circ}$ ) is assessed (see Fig. 1). Compared to 
Fig. 3 Comparison of maximal performance values Comparison of the current data with predicted values using formulas from earlier studies (Paterson et al. 1999; Neder et al. 1999; Wohlfahrt and Farazdaghi 2003; Myers et al. 2002). $P_{\max }$, maximal power output; $V_{\mathrm{O}_{2} \max }$, maximal oxygen consumption
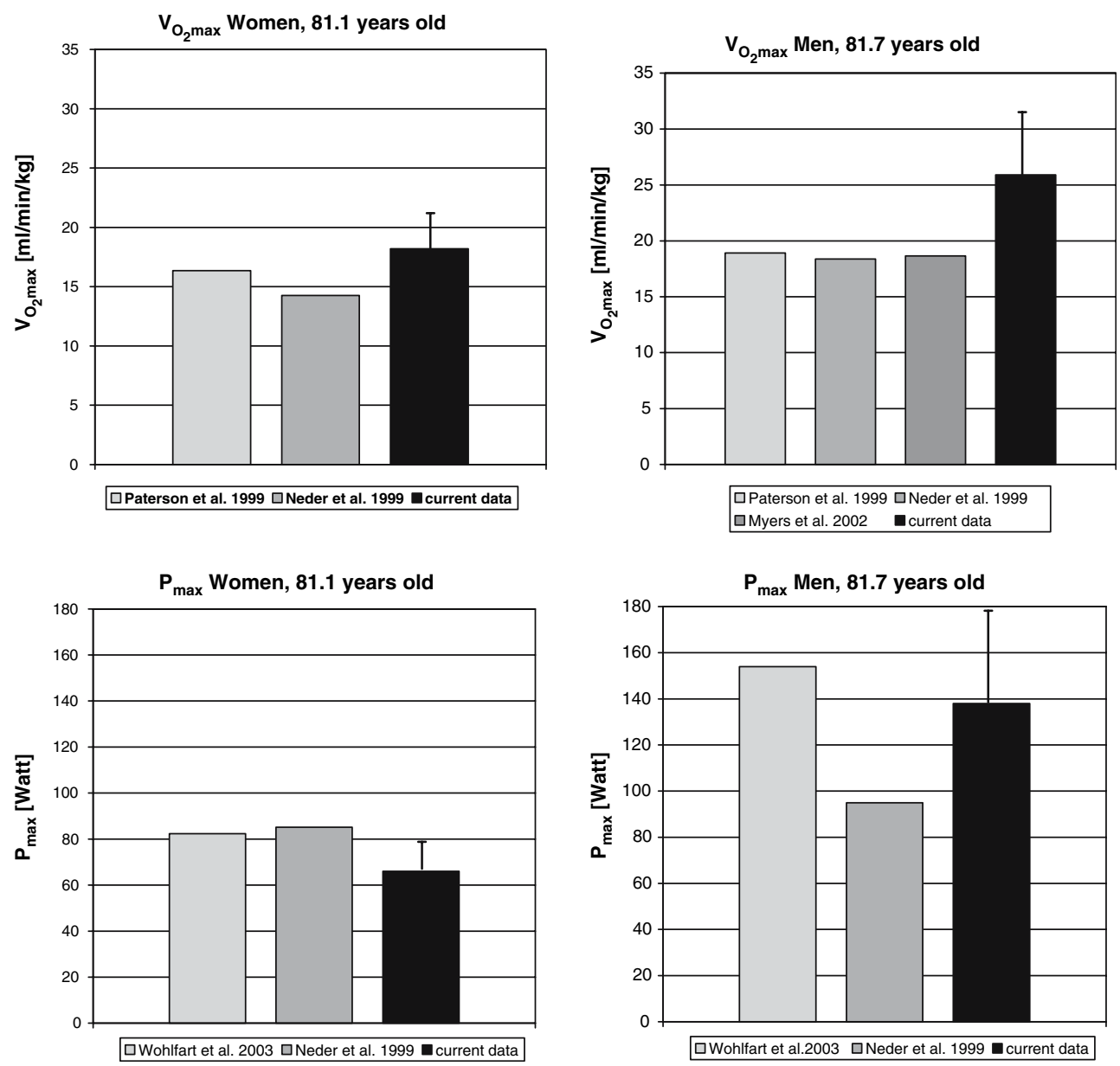

standard tests of MEL, we would therefore expect our values to be smaller by some $30 \%$. This approach was found to be safe and showed an excellent short and long-term test re-test reliability $\left(r^{2}=0.85\right)$.

We are aware of limitations of the study design in which we recruited independently living subjects (independently living, physically active and openminded for new experiences). The estimated parameters are hence superior to an average elderly population of $>75$ years. This assumption is confirmed by the high values, reached by our subjects in standard tests to determine the risk for falling (BBS, TUG) in community-dwelling populations. Except 1 out of 55 subjects, who scored only 36 points in the BBS and who needed $13.0 \mathrm{~s}$ in the TUG, all other subjects had score levels without any significant risk for falling (Shumway-Cook et al. 2000; Berg et al. 1992). However, the inclusion of subjects with regular medication intake may well represent an average population of independently living women and men of that age.

We found no significant impact of medication (i.e., beta-blockers, ACE inhibitors and statins) on maximal physical performance levels of the subjects, which could be expected according to previous studies (Teixeira et al. 1992; Kaiser 1984). This was evident as no significant difference for $V_{\mathrm{O}_{2} \max }$ between groups with a certain medication and the control group (without medication) was recorded (data not shown). This is according to what was reported by Taniguchi et al. (2003) and Phillips et al. (2004).

In conclusion, this study presents maximal performance values of a relatively large population of active and independent elderly Swiss subjects $>75$ years. A comparison with current predictions for maximal performance values for this age group shows that the data are above average for the population because of the good age-appropriate shape of our subjects. We could show that differences between female and male subjects for physiological performance parameters $\left(V_{\mathrm{O}_{2} \max }, P_{\max }, \mathrm{MEL}\right)$ are sex- and/or gender-specific and should be considered, e.g., when setting up training guidelines. In particular, this seems relevant for people $>75$ years, where men still record higher values than women even after normalization to lean body mass. 
Acknowledgments This project was supported by the National Research Programme NRP 53 "Musculoskeletal HelathChronic Pain" of the Swiss National Science Foundation (Project 405340-104718) and by the University of Bern, Switzerland. A special thank goes to MCL, Medizinische Laboratorien, Bern, Switzerland, for the reduced billing for blood analyses.

\section{References}

Astrand I (1960) Aerobic work capacity in men and women with special reference to age. Acta Physiol Scand 49(Suppl 169):1-92

Berg KO, Maki BE, Williams JI, Holliday PJ, Wood-Dauphinee SL (1992) Clinical and laboratory measures of postural balance in an elderly population. Arch Phys Med Rehabil 73:1073-1080

Borg GA (1982) Psychophysical bases of perceived exertion. Med Sci Sports Exerc 14:377-381

Buskirk ER, Hodgson JL (1987) Age and aerobic power: the rate of change in men and women. Fed Proc 46:1824-1829

Cicoira M, Davos CH, Florea V, Shamim W, Doehner W, Coats AJ, Anker SD (2001) Chronic heart failure in the very elderly: clinical status, survival, and prognostic factors in 188 patients more than 70 years old. Am Heart J 142:174-180

Ehsani AA, Spina RJ, Peterson LR, Rinder MR, Glover KL, Villareal DT, Binder EF, Holloszy JO (2003) Attenuation of cardiovascular adaptations to exercise in frail octogenarians. J Appl Physiol 95:1781-1788

Evans EM, Racette SB, Peterson LR, Villareal DT, Greiwe JS, Holloszy JO (2005) Aerobic power and insulin action improve in response to endurance exercise training in healthy 77-87 year olds. J Appl Physiol 98:40-45

Farazdaghi GR, Wohlfart B (2001) Reference values for the physical work capacity on a bicycle ergometer for women between 20 and 80 years of age. Clin Physiol 21:682-687

Fletcher GF, Balady GJ, Amsterdam EA, Chaitman B, Eckel R, Fleg J, Froelicher VF, Leon AS, Pina IL, Rodney R, Simons-Morton DA, Williams MA, Bazzarre T (2001) Exercise standards for testing and training: a statement for healthcare professionals from the American Heart Association. Circulation 104:1694-1740

Gulati M, Black HR, Shaw LJ, Arnsdorf MF, Merz CN, Lauer MS, Marwick TH, Pandey DK, Wicklund RH, Thisted RA (2005) The prognostic value of a nomogram for exercise capacity in women. N Engl J Med 353:468-475

Johnson PJ, Winter EM, Paterson DH, Koval JJ, Nevill AM, Cunningham DA (2000) Modelling the influence of age, body size and sex on maximum oxygen uptake in older humans. Exp Physiol 85:219-225

Kaiser P (1984) Physical performance and muscle metabolism during beta-adrenergic blockade in man. Acta Physiol Scand Suppl 536:1-53

Malbut KE, Dinan S, Young A (2002) Aerobic training in the 'oldest old': the effect of 24 weeks of training. Age Ageing 31:255-260

Morris CK, Myers J, Froelicher VF, Kawaguchi T, Ueshima K, Hideg A (1993) Nomogram based on metabolic equivalents and age for assessing aerobic exercise capacity in men. J Am Coll Cardiol 22:175-182

Myers J, Prakash M, Froelicher V, Do D, Partington S, Atwood JE (2002) Exercise capacity and mortality among men referred for exercise testing. N Engl J Med 346:793-801

Neder JA, Nery LE, Castelo A, Andreoni S, Lerario MC, Sachs A, Silva AC, Whipp BJ (1999) Prediction of metabolic and cardiopulmonary responses to maximum cycle ergometry: a randomised study. Eur Respir J 14:1304-1313

Neder JA, Nery LE, Peres C, Whipp BJ (2001) Reference values for dynamic responses to incremental cycle ergometry in males and females aged 20 to 80. Am J Respir Crit Care Med 164:1481-1486

Nordenfelt I, Adolfsson L, Nilsson JE, Olsson S (1985) Reference values for exercise tests with continuous increase in load. Clin Physiol 5:161-172

Paterson DH, Cunningham DA, Koval JJ, St Croix CM (1999) Aerobic fitness in a population of independently living men and women aged 55-86 years. Med Sci Sports Exerc 31:1813-1820

Phillips PS, Phillips CT, Sullivan MJ, Naviaux RK, Haas RH (2004) Statin myotoxicity is associated with changes in the cardiopulmonary function. Atherosclerosis 177:183-188

Rogers MA, Hagberg JM, Martin WH III, Ehsani AA, Holloszy JO (1990) Decline in $V_{\mathrm{O}_{2} \max }$ with aging in master athletes and sedentary men. J Appl Physiol 68:2195-2199

Shumway-Cook A, Brauer S, Woollacott M (2000) Predicting the probability for falls in community-dwelling older adults using the Timed Up \& Go Test. Phys Ther 80:896-903

Shvartz E, Reibold RC (1990) Aerobic fitness norms for males and females aged 6 to 75 years: a review. Aviat Space Environ Med 61:3-11

Simar D, Malatesta D, Dauvilliers Y, Prefaut C, Varray A, Caillaud C (2005) Aerobic and functional capacities in a selected active population of European octogenarians. Int J Sports Med 26:128-133

Steffen TM, Hacker TA, Mollinger L (2002) Age- and genderrelated test performance in community-dwelling elderly people: six-minute walk test, Berg balance scale, Timed Up \& Go Test, and gait speeds. Phys Ther 82:128-137

Taniguchi Y, Ueshima K, Chiba I, Segawa I, Kobayashi N, Saito M, Hiramori K (2003) A new method using pulmonary gasexchange kinetics to evaluate efficacy of beta-blocking agents in patients with dilated cardiomyopathy. Chest 124:954-961

Teixeira A, Billigmann PW, Bohner H, Schumacher H (1992) [Exercise performance after long-term administration of enalapril or metoprolol. A randomized double-blind study of hypertensive leisure-time sportsmen]. Dtsch Med Wochenschr 117:967-973

Torgrimson BN, Minson CT (2005) Sex and gender: what is the difference? J Appl Physiol 99:785-787

Uth $\mathrm{N}$ (2005) Gender difference in the proportionality factor between the mass specific $V_{\mathrm{O}_{2} \max }$ and the ratio between HR(max) and HR(rest). Int J Sports Med 26:763-767

Vinet A, Mandigout S, Nottin S, Nguyen L, Lecoq AM, Courteix D, Obert P (2003) Influence of body composition, hemoglobin concentration, and cardiac size and function of gender differences in maximal oxygen uptake in prepubertal children. Chest 124:1494-1499

Washburn RA, Seals DR (1984) Peak oxygen uptake during arm cranking for men and women. J Appl Physiol 56:954-957

Wiswell RA, Hawkins SA, Jaque SV, Hyslop D, Constantino N, Tarpenning K, Marcell T, Schroeder ET (2001) Relationship between physiological loss, performance decrement, and age in master athletes. J Gerontol A Biol Sci Med Sci 56:M618M626

Witham MD, McMurdo ME (2003) Pragmatic measures of outcome in trials of exercise training. Age Ageing 32:234-235

Wohlfart B, Farazdaghi GR (2003) Reference values for the physical work capacity on a bicycle ergometer for men-a comparison with a previous study on women. Clin Physiol Funct Imaging 23:166-170 